\title{
Noise Annoyance Caused by Amplitude Modulated Sounds Resembling the Main Characteristics of Temporal Wind Turbine Noise
}

\author{
Honorata HAFKE-DYS ${ }^{(1)}$, Anna PREIS ${ }^{(1)}$, Tomasz KACZMAREK ${ }^{(1)}$, \\ Adam BINIAKOWSKI ${ }^{(1)}$, Paweł KLEKA ${ }^{(2)}$ \\ (1) Institute of Acoustics \\ Adam Mickiewicz University \\ Umultowska 85, 61-114 Poznań, Poland; e-mail: \{h.hafke, apraton\}@amu.edu.pl \\ ${ }^{(2)}$ Institute of Psychology \\ Adam Mickiewicz University \\ Szamarzewskiego 89, 60-568 Poznań, Poland \\ (received June 10, 2015; accepted January 5, 2016)
}

\begin{abstract}
Annoyance ratings for artificially created noises, resembling the main characteristics of temporal wind turbine noise, were studied by means of a listening experiment involving 21 participants with normal hearing. Three types of stimuli were examined: broadband noise $(-4 \mathrm{~dB} /$ octave), noise generated by moving cars, and narrowband noise. All stimuli had the sound level fluctuations typical for wind turbine noise. The magnitude of the sound level fluctuations was measured in a quantitative way, by using the characteristics of amplitude modulated sound: modulation rate and modulation depth. Our aim was to examine how the modulation rate and the modulation depth influence the noise annoyance assessment of broadband and narrowband amplitude modulated noises. Three different modulation rates, $1,2 \mathrm{and} 4 \mathrm{~Hz}$, and sound level fluctuations (a measure of the modulation depth), 3, 6, $9 \mathrm{~dB}$, were applied to each type of stimuli (with exception of noise generated by the moving cars) and investigated. The participants in the listening experiment were presented with sound stimuli in laboratory conditions and asked to rate their annoyance on a numerical scale. The results have shown a significant difference between the investigated conditions. The effect was particularly strong between the annoyance judgments of different types of noise (narrow and broadband), and modulated versus unmodulated noises. Temporal fluctuations occurring in wind turbine noise are very pertinent to the perception of annoyance and could be responsible for its being a relatively annoying noise source. The obtained results were discussed and compared to the typical modulation rates and level changes that occur in recordings of real wind turbine noise.
\end{abstract}

Keywords: wind turbines amplitude modulation; noise annoyance.

\section{Introduction}

The dose-response curves obtained for wind turbine noise are different from similar curves obtained for other environmental sound sources, such as traffic noise, railway noise or even air noise. They show systematically a larger proportion of highly annoyed people (\%HA) at the same dose value of $L_{d e n}$ compared to other noise sources (MiEDEMA, OUdSHOORN, 2001; Miedema, Vos, 2004; Pedersen, PerssonWaye, 2004; Pedersen et al., 2009; Janssen et al., 2011). There are several acoustical and non-acoustical factors often mentioned in this context that could explain the unexpectedly high annoyance assessment for wind turbine noise. Among non-acoustical factors, the most frequently mentioned are: attitude toward wind turbines (Pedersen, Persson-Waye, 2007; PederSEN et al., 2009; 2010), economic benefits (PEDERSEN et al., 2009; JANSSEN et al., 2011) and visual settings (Pedersen, Persson-Waye, 2007; Pedersen, Larsman, 2008; VAN DEN Berg, 2009; JANSSEN et al., 2011). Among acoustical factors the most important seem to be: the low frequency content (SALT, Hullar, 2010; Bolin et al., 2011; Møller, Peder- 
SEN, 2011), and temporal fluctuations of sound level (Moorhouse et al., 2007). Some researchers also mention the presence of a discrete frequency component in wind turbine noise (HubBARD, SHEPHERD, 1991). Regarding the low frequency content in wind turbine noise, there is a tendency in the literature to agree that this is not a problem related to increase annoyance of this specific sound source (JACOBSEN, 2005; Tachibana, 2014). However, this is not the case when the temporal fluctuations of the sound level are considered. There have been many studies discussing whether or not amplitude modulation is perceived in wind turbine noise. VAN DEN BERG (2009) concluded that amplitude modulation is perceptible within dwellings. Moorhouse et al. (2007) have a different opinion. In very recent studies performed in Japan (TACHIBANA, 2014) it was found that "the fluctuation sensation by amplitude modulated sound might be caused at about three-quarters of all the measuring points" (the number of all measuring points was 81). On the other hand, it is clear that the presence of sound level fluctuations in wind turbine noise depends on many factors, such as wind speed, meteorological conditions, the distance from the sound source to the receiver etc. Assuming that such conditions occur and sound level fluctuations are present in wind turbine noise, it is possible to measure how these fluctuations are perceived by people. Several attempts were made in the past; for example, psychoacoustic characteristics such as roughness, fluctuation strength and loudness of wind turbine noise were investigated in laboratory settings (PERsonWAYE, ÖHrströM, 2002). Although the main effect was confirmed, i.e. that the same sound level of wind turbine noise does not correspond to the same annoyance assessment, no specific relationships between the investigated sound characteristics and wind turbine noise annoyance were established. On the other hand, there are studies which show that fluctuation strength (FASTL, ZWICKER, 2007) is a good descriptor of a fluctuating wind turbine noise and such fluctuations can be easily picked up by human listeners (VAN DEN BERG, 2005).

A simplified equation for the fluctuation strength of broadband noise can be written as (FASTL, ZwICKER, 2007)

$$
\mathrm{F}_{\mathrm{BBN}}=0.072(\Delta L-3.6) \text { vacil, }
$$

where vacil is the unit of fluctuation strength. 1 vacil equals the absolute fluctuation strength reference value produced by a $60 \mathrm{~dB}, 1 \mathrm{kHz}$ tone, $100 \%$ amplitude modulated at $4 \mathrm{~Hz}$ (FAsTL, ZwICKER, 2007). Van den Berg has shown that when $\Delta L$ rises from $3 \mathrm{~dB}$ to $6 \mathrm{~dB}$ the $\mathrm{F}_{\mathrm{BBN}}$ rises from 0 to 0.17 vacil. According to other studies (LEGARTH, 2007; LEE et al., 2011), fluctuation strength correlates very well with the "swish- ing character" of the noise perceived by listeners. "Swishing", "whistling" and "pulsating/throbbing" are the words usually used for describing wind turbine noise characteristics (PEDersen, Person Waye, 2004).

On the other hand, it is a well-established fact that steady state sounds evoke a different amount of annoyance than fluctuating sounds. It has been shown in laboratory experiments that the same annoyance ratings for steady state sounds and fluctuating sounds were obtained when the sound level of the steady state sound was $5 \mathrm{~dB}$ higher than the sound level of the fluctuating sound (Moorhouse et al., 2007). According to other studies, when the fluctuations were measured by the value of standard deviation (sd), the sounds of 4sd were assessed as more annoying than the sounds of 2 sd. The loudness of these two types of sounds was the same (DiTTRICH et al., 2009).

The current study extends the previous work, trying to answer some significant questions about the characteristics of wind turbine noise in relation to the noise annoyance assessment of amplitude modulated sounds:

1. What is the relationship between the noise annoyance ratings of amplitude modulated sounds, modulation rate and modulation depth?

2. Does noise annoyance caused by amplitude modulated sounds depend on the type of sound (narrow band noise, broadband noise, car noise)?

3. Which psychoacoustic noise characteristics correlate with the noise annoyance assessment of amplitude modulated sounds?

4. How do these characteristics relate to real wind turbine noise?

To answer these questions, a psychoacoustic experiment was performed in which three types of stimuli were examined: broadband noise $(-4 \mathrm{~dB} /$ octave), noise generated by moving cars, and narrowband noise. Broadband noise and narrowband noises were modulated with three different modulation frequencies, 1, 2 and $4 \mathrm{~Hz}$, and sound level fluctuations (measure of the modulation depth), 3, 6, $9 \mathrm{~dB}$, and the car noise stimuli were adjusted to have the same characteristics as the modulated stimuli.

Our aim was to examine how modulation rate and modulation depth influence the noise annoyance assessment of broadband as well as narrowband amplitude modulated noises. Finally, by having car noise as stimuli, with level fluctuations identical to the temporal characteristics of modulated noises, but with different spectra, it was possible to test the influence of the spectrum characteristics of the investigated stimuli on noise annoyance assessment.

In order to examine the possible psychoacoustic characteristics responsible for the noise annoyance assessment of the investigated stimuli, the following five 
sound characteristics were calculated: loudness, $N$, the percentile of loudness, (N5), fluctuation strength, $F$, roughness, $R$, and sharpness, $S$. Since all these characteristics are component dimensions of psychoacoustic annoyance, $P A$, a multicomponent annoyance indicator (FASTL, ZWICKER, 2007), also the $P A$ was calculated for all the investigated stimuli. Psychoacoustic annoyance, $P A$ is defined as follows:

$$
A=N_{5}\left(1+\sqrt{w_{S}^{2}+w_{F R}^{2}}\right)
$$

with $N_{5}$ percentile loudness in sones, $w_{S}$ describing the effect of sharpness $S$

$$
\begin{array}{r}
w_{S}=\left(\frac{S}{\text { acum }}-1.75\right) 0.25 \lg \left(\frac{N_{5}}{\text { sone }}+10\right) \\
\text { for } S>1.75 \text { acum, }
\end{array}
$$

$w_{F R}$ describing the influence of fluctuation strength $F$ and roughness $R$

$$
w_{F R}=\frac{2.18}{\left(N_{5} / \text { sone }\right)^{0.4}}\left(0.4 \frac{F}{\text { vacil }}+0.6 \frac{R}{\text { asper }}\right) \text {. }
$$

The correlation between the calculated noise characteristics and noise annoyance assessment was tested and discussed.

\section{Method}

\subsection{Stimuli and equipment}

Three types of stimuli were used in this study: noise generated by moving cars, artificially synthesized broadband noise $(-4 \mathrm{~dB} /$ octave), and narrowband noises with three different center frequencies: $500 \mathrm{~Hz}, 2000 \mathrm{~Hz}$ and $8000 \mathrm{~Hz}$. The noise generated by moving cars, $M C$, was chosen in order to a test hypothesis about the similarity of sound level fluctuation occurring in wind turbine noise and sound level fluctuation caused by different distances between the passingby cars. The broadband noise, $B N$, was chosen based on the assumption that the noise $(-4 \mathrm{~dB} /$ octave $)$ resembles the frequency characteristics of general wind turbine noise (YokOYAma et al., 2013). Finally, the narrowband noises, NN_500, NN_2000, NN_8000, were chosen in order to find out whether the assessment of noise annoyance depends on the frequency band in which the amplitude modulation occurs.

Psychoacoustics has established that the threshold of amplitude modulation detection is the lowest at a modulation rate of $4 \mathrm{~Hz}$ (FASTL, ZwiCKER, 2007). The remaining question concerns annoyance assessment at different modulation rates: will the annoyance ratings increase or decrease with the increasing modulation rate? To test this hypothesis in this study three modulation rates $(1,2$ and $4 \mathrm{~Hz})$ were applied to the investigated stimuli: BN, NN and MC. MC noise was created in such a way that the pauses between cars formed the level fluctuations identical as in modulated noises.

Three values of sound level fluctuations, $\Delta L$ of 3,6 and $9 \mathrm{~dB}$ were chosen based on the analysis of real wind turbine noise recordings (the stimulus used in VAN RENTERGhem et al. (2013) is presented in Fig. 1).

The results of this analysis confirm the already well-known fact that the maximum sound level occurs in the frequency range between $2-6 \mathrm{kHz}$ (Fig. 1) and that the maximum sound level fluctuation of total noise occurs at a modulation rate of $1 \mathrm{~Hz}$. For this modulation rate $(1 \mathrm{~Hz})$ the magnitude of sound level fluctuations was analyzed in the $1 / 3$ octave-band (Fig. 2). It turns out that the local maxima occur at $2000 \mathrm{~Hz}$ and $8000 \mathrm{~Hz}$.

Based on this result, the center frequencies of the narrowband noises were chosen. A frequency band centered at $500 \mathrm{~Hz}$ was added as a representation of the low frequency components. The same characteristics of amplitude modulation: modulation rate, $f_{m}$, and sound level fluctuation, $\Delta L$, were applied to the broadband noise and to narrowband noises. The noise generated by moving cars was adjusted to generate a similar time distance (compared to the modulation rate) between the single pass-bys: $1 \mathrm{~s}, 500 \mathrm{~ms}$ and $250 \mathrm{~ms}$. The level fluctuation was adjusted by changing the speed of the simulated single pass-by.

For each type of stimulus there was one unmodulated stimulus (with modulation rate and sound level fluctuation equal to 0: MC_0_0, BN_0_0, NN_500_0_0, NN_2000_0_0, NN_8000_0_0) and nine modulated stimuli with three modulation frequencies $\left(f_{m}=1,2\right.$, $4 \mathrm{~Hz})$ and three values of sound level fluctuation $(3,6$, $9 \mathrm{~dB})$. The investigated stimuli were described as follow: MC_1_3 means Moving Car stimulus with a time distance between the cars corresponding to the modulation rate of $\mathbf{1 ~ H z}$ and with the sound level fluctuation equal to $3 \mathrm{~dB}$. The same type of description was applied to all the stimuli.

Before the experiment, an objective analysis of all the stimuli was performed with the use of the Head Acoustic software, Artemis Analyzer. Loudness, $N$, fluctuation strength, $F$, roughness, $R$, sharpness, $S$, and psychoacoustic annoyance, PA (FASTL, ZWICKER, 2007), were calculated. For all the mentioned sound characteristics the averaged values were calculated. Only for loudness did the percentile (N5) value have to be additionally calculated in order to assess the psychoacoustic annoyance value, PA, (FAstL, Zwicker, $2007)$. The results of all the calculations are presented in Table 1.

The sound characteristics of the MC and BN stimuli are presented in Figs. 3 and 4 respectively. It can be seen (Fig. 1 and Figs. 3 and 4 ) that the $1 / 3$ octave- 

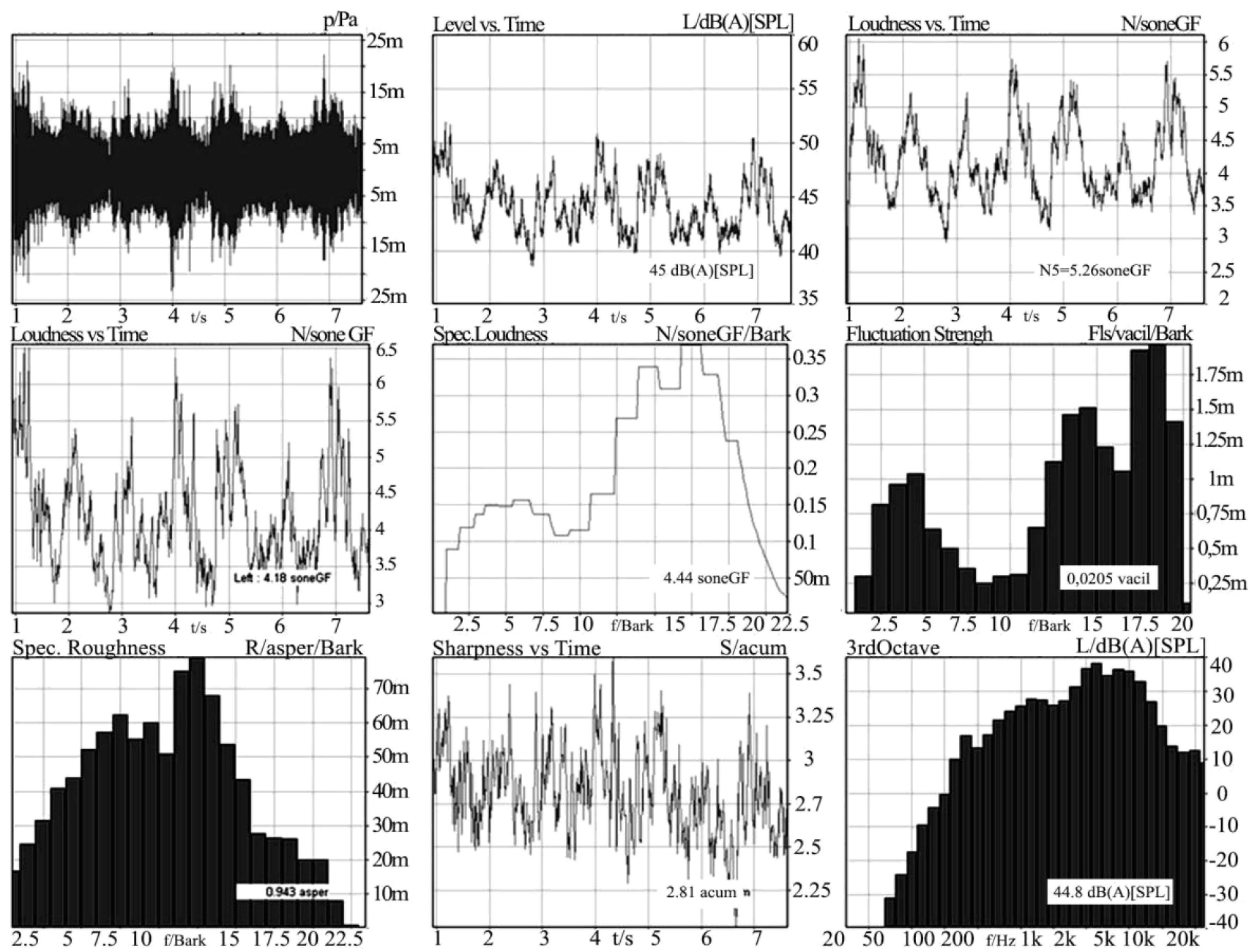

Fig. 1. Sound characteristics of the real Wind Turbine Noise (WTN) recording (based on the stimulus used by VAN Renterghem et al., 2013). The calculated values were: sound level $L$ (dBA), the loudness value reached or exceeded in $5 \%$ of the measurement time, $N 5$, specific loudness, $N$, specific fluctuation strength, $F$, specific roughness, $R$, sharpness, $S$, and $1 / 3$ octave-band spectrum.

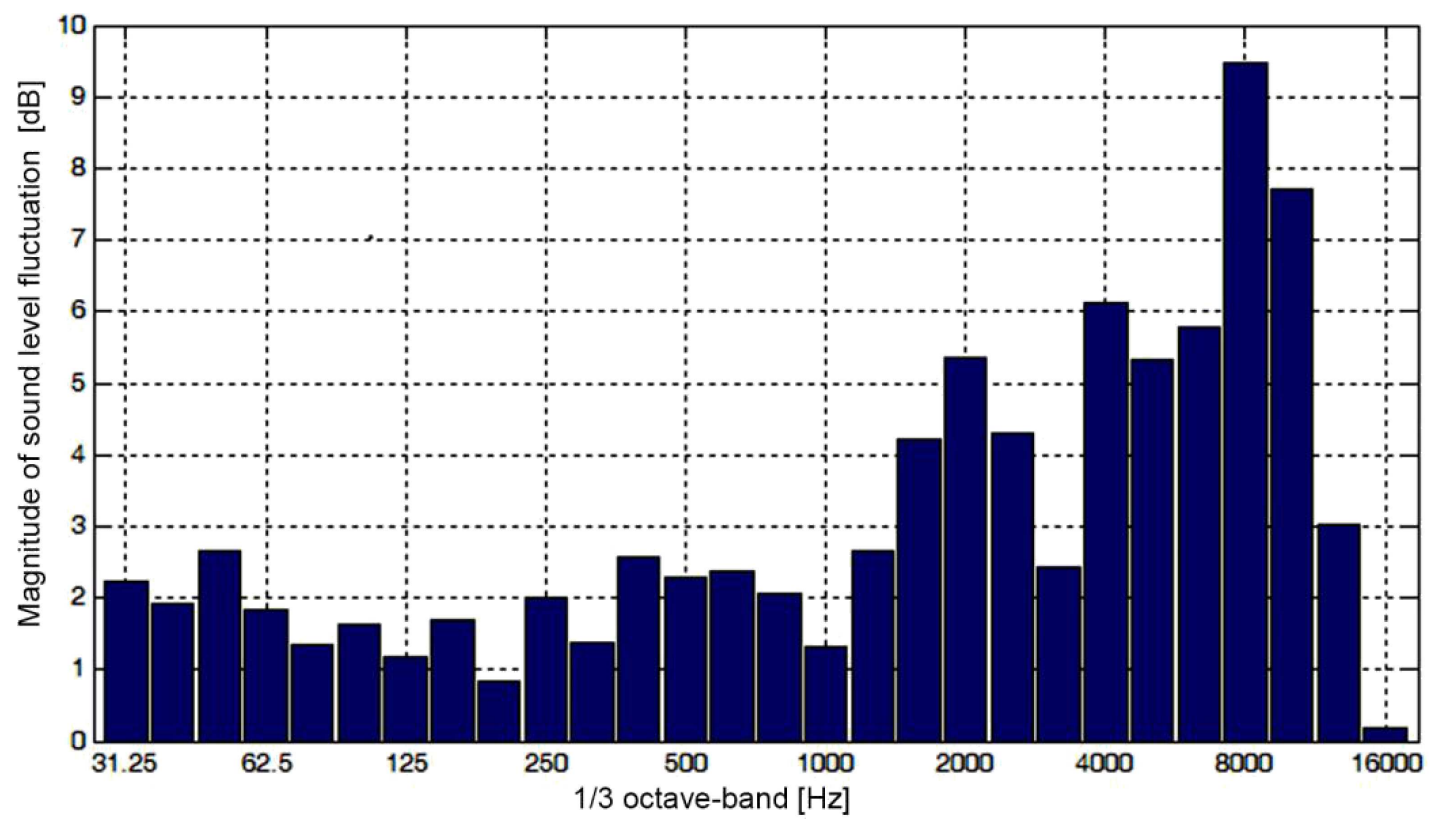

Fig. 2. Magnitude of sound level fluctuation (for $f_{m}=1 \mathrm{~Hz}$ ) versus $1 / 3$ octave-band. 
Table 1. Sound characteristics calculated for all investigated stimuli and extra added calculations for WTN stimulus

(last column, marked in bold).

\begin{tabular}{|c|c|c|c|c|c|c|c|c|c|c|c|}
\hline & MC_00 & MC_13 & MC_16 & MC_19 & MC_23 & MC_26 & MC_29 & MC_43 & MC_46 & MC_49 & WTN_19 \\
\hline N5 & 4.08 & 4.38 & 4.74 & 5.23 & 4.44 & 4.76 & 5.22 & 4.42 & 4.81 & 5.12 & 5.26 \\
\hline $\mathbf{N}$ & 3.98 & 3.92 & 3.91 & 3.93 & 3.95 & 4.0 & 4.03 & 3.96 & 4.05 & 4.04 & 4.44 \\
\hline $\mathbf{F}$ & 0.0163 & 0.015 & 0.0187 & 0.0238 & 0.0294 & 0.0454 & 0.0866 & 0.0523 & 0.183 & 0.334 & 0.0205 \\
\hline $\mathbf{R}$ & 1.1 & 1.11 & 1.08 & 1.06 & 1.1 & 1.12 & 1.11 & 1.14 & 1.21 & 1.64 & 0.943 \\
\hline $\mathrm{S}$ & 2.23 & 2.22 & 2.22 & 2.22 & 2.24 & 2.25 & 2.25 & 2.23 & 2.29 & 2.24 & 2.81 \\
\hline \multirow[t]{2}{*}{$\mathbf{P A}$} & 7.5 & 7.98 & 8.43 & 9.1 & 8.08 & 8.66 & 9.41 & 8.22 & 9.35 & 11.65 & 9.04 \\
\hline & BN_00 & BN_13 & BN_16 & BN_19 & BN_23 & BN_26 & BN_29 & BN_43 & BN_46 & BN_49 & \\
\hline N5 & 5.46 & 5.82 & 6.21 & 6.49 & 5.74 & 6.05 & 6.26 & 5.66 & 5.87 & 6.02 & \\
\hline $\mathbf{N}$ & 5.32 & 5.31 & 5.31 & 5.31 & 5.31 & 5.31 & 5.31 & 5.31 & 5.31 & 5.31 & \\
\hline $\mathbf{F}$ & 0.0208 & 0.0257 & 0.0338 & 0.0447 & 0.0285 & 0.0487 & 0.078 & 0.0305 & 0.0672 & 0.124 & \\
\hline $\mathbf{R}$ & 1.16 & 1.19 & 1.18 & 1.17 & 1.19 & 1.19 & 1.2 & 1.2 & 1.21 & 1.24 & \\
\hline $\mathbf{S}$ & 2.44 & 2.44 & 2.44 & 2.43 & 2.44 & 2.44 & 2.43 & 2.44 & 2.44 & 2.43 & \\
\hline \multirow[t]{2}{*}{ PA } & 9.86 & 10.52 & 11.09 & 11.49 & 10.41 & 10.92 & 11.35 & 10.32 & 10.77 & 11.25 & \\
\hline & NN_500 & NN_513 & NN_516 & NN_519 & NN_523 & NN_526 & NN_529 & NN_543 & NN_546 & NN_549 & \\
\hline N5 & 1.96 & 2.06 & 2.14 & 2.22 & 2.04 & 2.12 & 2.2 & 2.01 & 2.07 & 2.1 & \\
\hline $\mathbf{N}$ & 1.79 & 1.82 & 1.82 & 1.82 & 1.82 & 1.82 & 1.82 & 1.82 & 1.82 & 1.82 & \\
\hline $\mathbf{F}$ & 0.0217 & 0.0275 & 0.0354 & 0.046 & 0.0304 & 0.0509 & 0.0814 & 0.0252 & 0.0507 & 0.0972 & \\
\hline $\mathbf{R}$ & 0.201 & 0.203 & 0.201 & 0.199 & 0.203 & 0.203 & 0.203 & 0.206 & 0.21 & 0.216 & \\
\hline $\mathbf{S}$ & 0.506 & 0.506 & 0.506 & 0.504 & 0.507 & 0.506 & 0.504 & 0.507 & 0.506 & 0.505 & \\
\hline \multirow[t]{2}{*}{$\mathbf{P A}$} & 2.38 & 2.51 & 2.6 & 2.7 & 2.49 & 2.61 & 2.74 & 2.45 & 2.56 & 2.67 & \\
\hline & NN_2000 & NN_213 & NN_216 & NN_219 & NN_223 & NN_226 & NN_229 & NN_243 & NN_246 & NN_249 & \\
\hline N5 & 1.86 & 1.92 & 2.02 & 2.1 & 1.92 & 2.01 & 2.07 & 1.92 & 1.97 & 2.01 & \\
\hline $\mathbf{N}$ & 1.65 & 1.64 & 1.64 & 1.64 & 1.64 & 1.64 & 1.65 & 1.64 & 1.64 & 1.65 & \\
\hline $\mathbf{F}$ & 0.0106 & 0.0096 & 0.0121 & 0.0162 & 0.0109 & 0.02 & 0.0345 & 0.0174 & 0.0469 & 0.0909 & \\
\hline $\mathbf{R}$ & 0.339 & 0.34 & 0.338 & 0.335 & 0.34 & 0.34 & 0.341 & 0.341 & 0.344 & 0.351 & \\
\hline $\mathrm{S}$ & 1.96 & 1.96 & 1.95 & 1.95 & 1.96 & 1.95 & 1.95 & 1.96 & 1.95 & 1.95 & \\
\hline \multirow[t]{2}{*}{$\mathbf{P A}$} & 2.53 & 2.6 & 2.72 & 2.82 & 2.6 & 2.72 & 2.82 & 2.61 & 2.71 & 2.84 & \\
\hline & NN_8000 & NN_813 & NN_816 & NN_819 & NN_823 & NN_826 & NN_829 & NN_843 & NN_846 & NN_849 & \\
\hline N5 & 1.5 & 1.56 & \begin{tabular}{|l|}
1.64 \\
\end{tabular} & 1.7 & \begin{tabular}{|l|l|}
1.54 \\
\end{tabular} & \begin{tabular}{|l|l|}
1.6 \\
\end{tabular} & \begin{tabular}{l|l}
1.65 \\
\end{tabular} & 1.53 & 1.58 & 1.61 & \\
\hline $\mathbf{N}$ & 1.2 & 1.2 & 1.19 & 1.19 & 1.19 & 1.19 & 1.19 & 1.2 & 1.2 & 1.2 & \\
\hline $\mathbf{F}$ & 0.0023 & 0.0024 & 0.0029 & 0.0036 & 0.0027 & 0.0042 & 0.0065 & 0.0036 & 0.008 & 0.0143 & \\
\hline $\mathbf{R}$ & 0.107 & 0.111 & 0.11 & 0.109 & 0.111 & 0.111 & 0.112 & 0.112 & 0.114 & 0.117 & \\
\hline $\mathbf{S}$ & 7.57 & 7.57 & 7.57 & 7.57 & 7.57 & 7.57 & 7.57 & 7.57 & 7.57 & 7.57 & \\
\hline $\mathbf{P A}$ & 3.82 & 3.98 & 4.19 & 4.35 & 3.93 & 4.09 & 4.22 & 3.9 & 4.03 & 4.11 & \\
\hline
\end{tabular}

band spectra (with A-correction) of real WTN and MC and BN stimuli are similar, however, their loudness patterns are different. On the other hand, when comparing the calculated sound characteristics for WTN (the last column in Table 1) with the values obtained for the investigated stimuli, they are similar to the BN and MC stimuli.

\subsection{Participants}

Twenty-one participants (aged between 19 and 24 years) took part in the experiment. All participants qualified as having normal hearing (normal hearing was defined as the audiometric threshold of $20 \mathrm{~dB} \mathrm{HL}$, or better, in a frequency range from 250 to $8000 \mathrm{~Hz}$, according to the ANSI standard (ANSI, 1996), and were paid for their participation. The results of only 19 participants were included in the final analysis. Two participants were excluded on the basis of the interraters agreement index (KRIPPENDORFF, 1980). After excluding these participants from the group, the Alfa Cronbacha index ( $\mathrm{R}$ Core Team 2015) increased from 0.296 to 0.341 . 


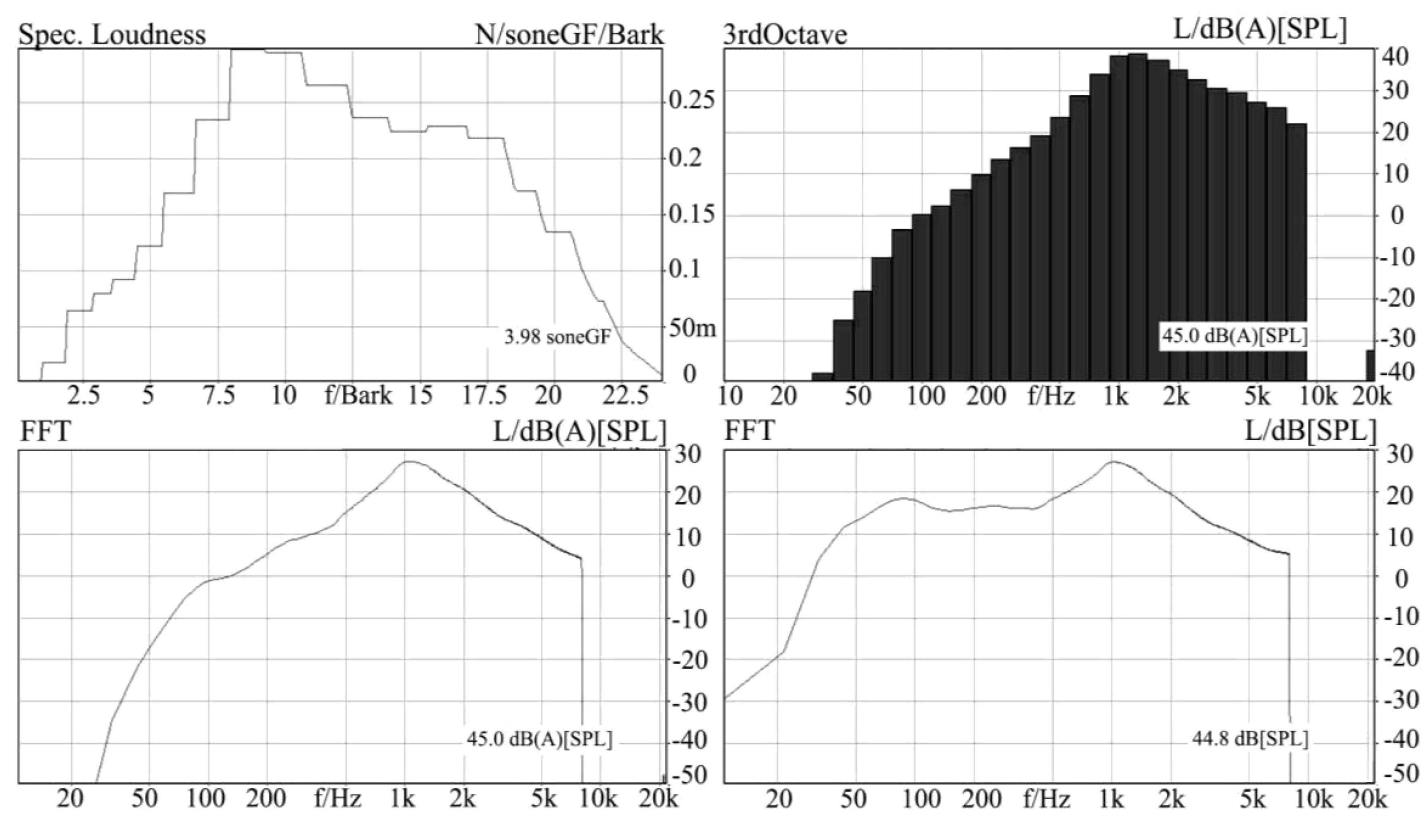

Fig. 3. Sound characteristics of the MC_00 stimulus: specific loudness, $1 / 3$ octave-band spectrum, $(\mathrm{dBA}), \mathrm{FFT},(\mathrm{dBA}), \mathrm{FFT},(\mathrm{dB})$.

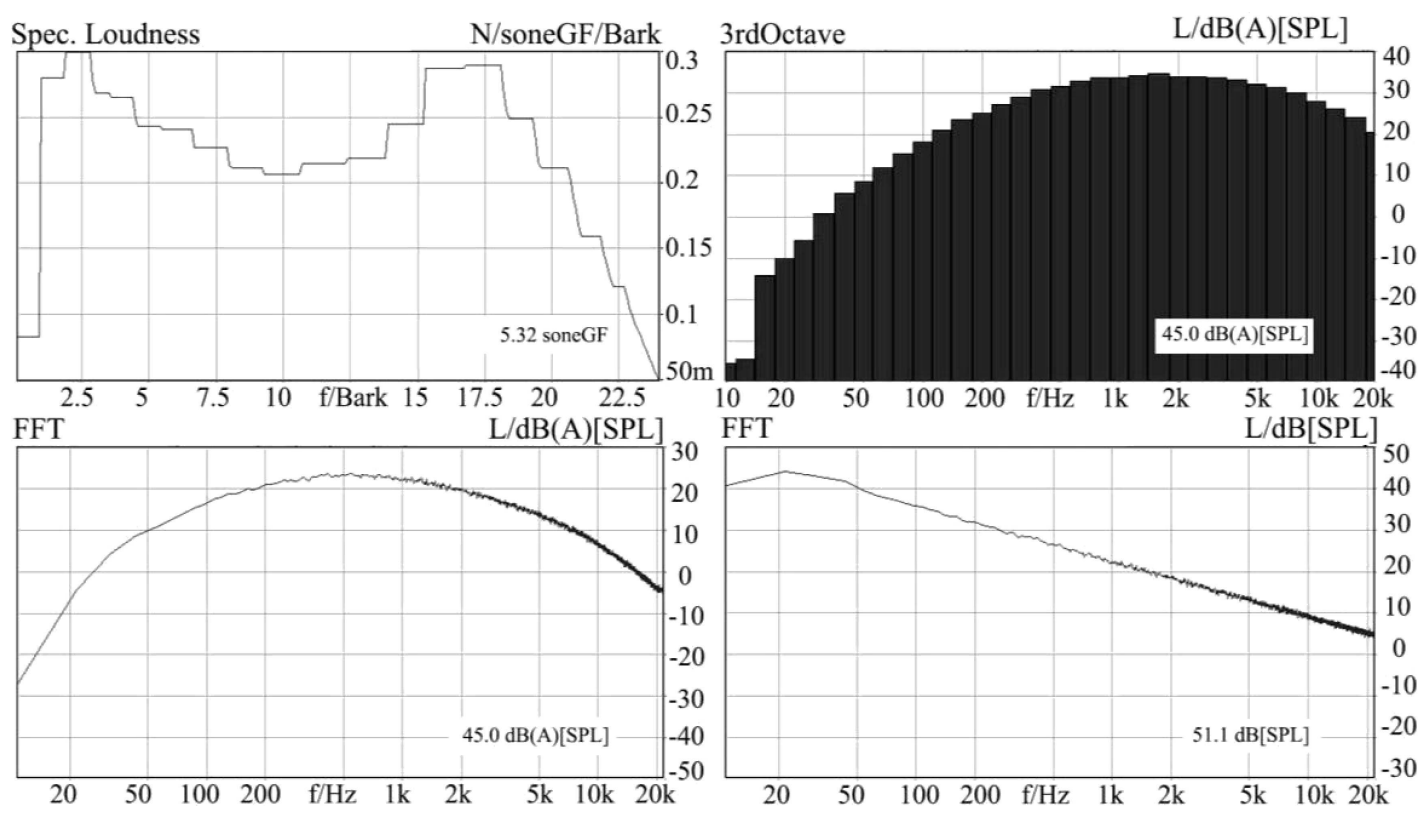

Fig. 4. Sound characteristics of the BN_00 stimulus: specific loudness, $1 / 3$ octave-band spectrum, $(\mathrm{dBA}), \mathrm{FFT},(\mathrm{dBA}), \mathrm{FFT},(\mathrm{dB})$.

\subsection{Procedure}

In the psychoacoustic experiment the participants judged the annoyance of 50 different noises. Each stimulus was presented 10 times. All together 500 stimuli were presented to the participants, in random order. The whole experiment was carried out in ten 7-minute sessions. After each session there was a short break lasting a few minutes. After five sessions there was 20minute break. The participants were seated in armchairs, in a $32 \mathrm{~m}^{2}$ damped room and judged the annoyance in each scenario using an 11-point (0-10) nu- merical scale. The scale used in this study has been recommended for noise surveys by ICBEN (FIELDS et al., 2001; PreIs et al., 2003) and defined in the ISO/TS 15666:2003(E) standard (ISO, 2003). However, the question about annoyance was adapted to the laboratory situation, e.g. there was no question about the last 12 months but rather about the present situation. In accordance with recommendations from earlier studies (BERGLund et al., 1976; HELlman, 1982) and with the ICBEN recommendations (FIELDs et al., 2001; PREIS et al., 2003) the participants were given the following instructions: Please sit comfortably in the armchair. 
Imagine that you are resting at home. You will hear road traffic noise. What number from zero to ten best shows how much you are bothered, disturbed, or annoyed by the noise? If you are not at all annoyed choose zero, if you are extremely annoyed choose ten, if you are somewhere in between, choose a number between zero and ten. In order to avoid simple loudness scaling, the instructions were carefully explained to the listeners. The signals were presented via Sennheiser HD600 open headphones and were sent from the computer through a Head Acoustic PEQ IV.1 programmable equalizer. After the calibration procedure the $L_{A e q, T}$ level of each scenario corresponded to $45 \mathrm{dBA}$.

\section{Results}

From the psychoacoustic experiment the annoyance ratings for 50 different noises were obtained. The results of 10 repetitions of each type of noise were then averaged, giving 50 average annoyance ratings for each participant. The results were grand mean-centered. This means that normalizing coefficients were created for each participant by dividing the overall mean of all the results by the mean of the results obtained from a given listener. Then the results of a given listener were multiplied by these factors.
At first the repeated measures rANOVA design was applied to analyze the noise annoyance assessment obtained for each type of sound separately (see Fig. 5). A specific pair comparison was based on contrast analysis.

Results obtained for moving cars (MC)

The repeated measures rANOVA design resulted in a significant main effect - namely for modulation rate, $[F(1.2,21.3)=12.72, p=0.001$, eta2 $=.414]$ and sound level fluctuation $[F(1.3,23.2)=14.31$, $p<0.001$, eta $2=.443]$. There were also significant effects for the interaction between those two factors $[F(2.4,43.9)=10.07, p<0.001$, eta $2=.359]$. Generally, annoyance increases when frequency and modulation depth increase. The differences between unmodulated noise and modulated noises are significant in all but one cases. There was no difference between MC_0_0 and MC_1_3 $(p=0.086)$.

Results obtained for broadband noise (BN)

The repeated measures rANOVA design resulted in a significant main effect - namely for modulation rate, $[F(1.4,25.7)=10.24, p=0.001$, eta2 $=0.363]$ and sound level fluctuation $[F(1.7,30.3)$ $=10.67, p=0.001$, eta $2=0.372]$. There were also

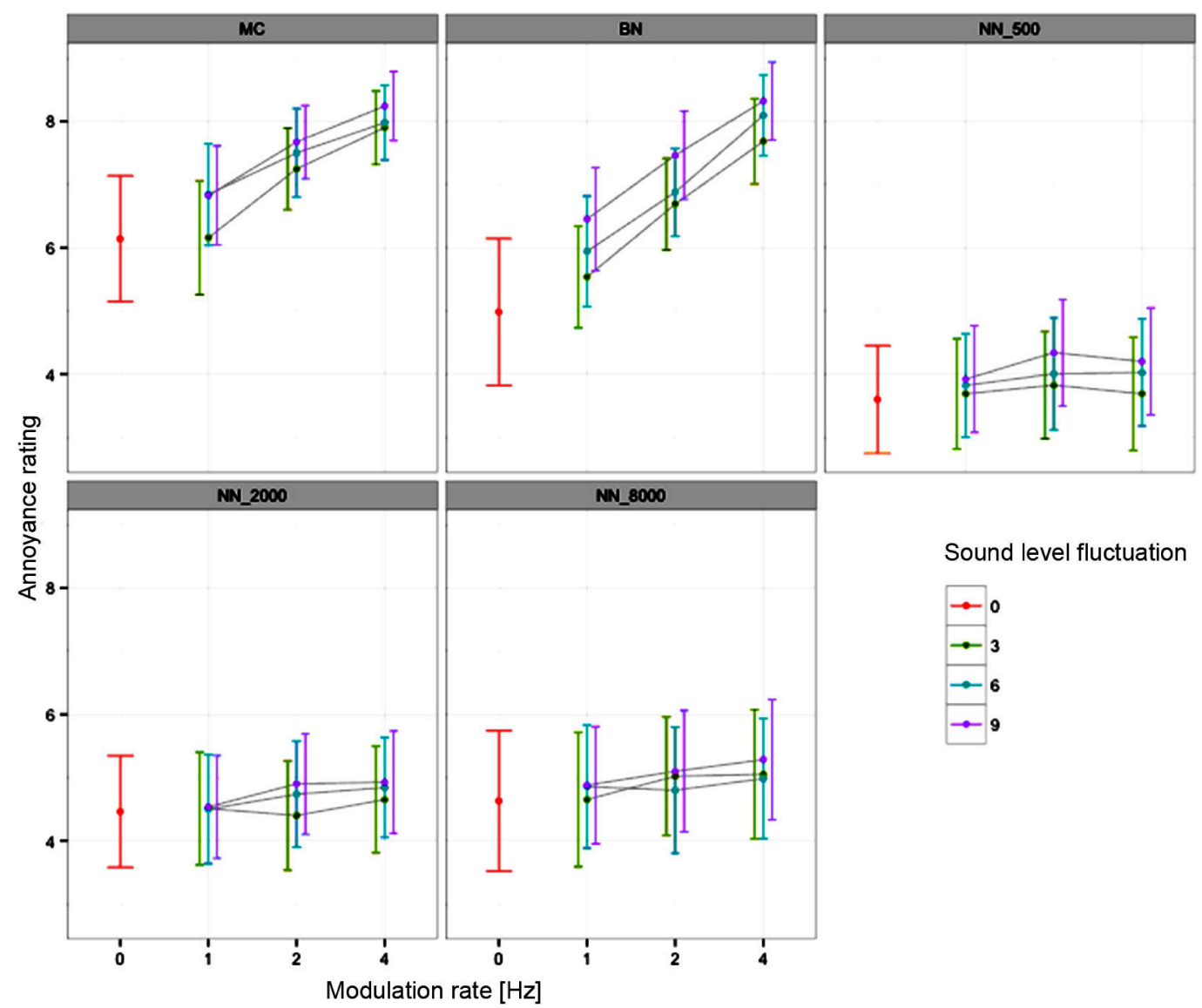

Fig. 5. Mean annoyance ratings with 95\% CI for five different types of investigated stimuli: MC, BN, NN_500, NN_2000, NN_8000. 
significant effects for the interaction between those two factors $[F(3.4,62.7)=6.12, p<0.001$, eta2 $=0.254]$. Generally, annoyance increases when frequency and modulation depth increase. The differences between unmodulated noise and modulated noises are significant in all cases except for the stimuli BN_1_3, BN_1_6 and BN_1_9 $(p>0.05)$.

\section{Results obtained for narrowband noise (NN_500)}

The repeated measures rANOVA design resulted in a significant main effect - namely for modulation rate, $[F(3,54)=5.31, p=0.003$, eta $2=0.228]$ and sound level fluctuation $[F(3,54)=5.70, p=0.002$, eta $2=$ $0.241]$. There were also significant effects for the interaction between those two factors $[F(9,162)=4.60$, $p<0.001$, eta $2=0.204]$. A significant difference between unmodulated and modulated signals occur only in three cases: for NN_500_1_9 $(p=0.012)$, N_500_2_9 $(p=0.003)$ and NN_500_4_9 $(p<0.001)$.

\section{Results obtained for narrowband noise (NN_2000)}

The repeated measures rANOVA design resulted in a significant main effect for sound level fluctuation $[F(2.3,49,9)=3.27, p=0.043$, eta $2=0.154]$ but not for the modulation rate $[F(2,35.4)=2.31$, $p=0.115]$. However, there is a significant interaction effect between factors $[F(4.3,76.8)=3.52, p=0.009$, eta2 $=0.164]$. A significant difference between unmodulated and modulated signals occurs only in two cases: NN_2000_2_9 $(p=0.006)$ and NN_2000_4_9 $(p=0.022)$.

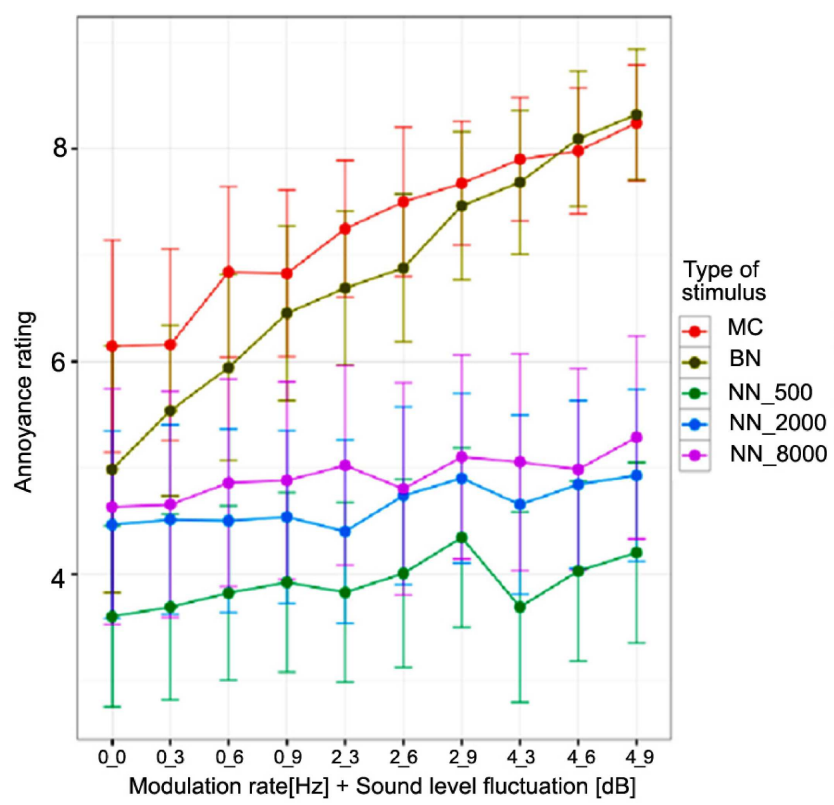

\section{Results obtained for narrowband noise (NN_8000)}

The repeated measures rANOVA design resulted in a non-significant main effect for both factors' modulation rate $[F(1.9,35.0)=1.98, p=0.155]$ and sound level fluctuation $[F(1.9,34.3)=2.0, p=0.153]$.

Finally, the rANOVA was applied to all the results with the type of sound as a factor and an index representing the measure of disturbance arranged as follows: 0_0, 1_3, 1_6, 1_9, 2_3, 2_6, 2_9, 4_3, 4_6, 4_9 as a covariate. The results are presented in Fig. 6. There is a significant main effect for the type of sound, $[F(4,944)$ $=173.7, p<0.001$, eta $2=0.424]$. However, the post hoc analysis shows only small differences between MC and $\mathrm{BN}$ stimuli $(p=0.047)$ for lower modulation rates and there are no differences at all between NN_8000 and NN_2000 $(p=0.079)$. However, the differences are significant between the remaining pairs $(p=0.001)$.

To identify the other possible noise characteristics responsible for the noise annoyance assessments of the investigated noise scenarios the correlation coefficients between all the objective measures presented in Table 1 and the annoyance ratings were calculated. The calculated correlation coefficients are presented in Table 2.

Table 2. Correlation coefficients for ICBEN annoyance ratings and noise characteristics calculated for each type of stimuli.

\begin{tabular}{|c|c|c|c|c|c|c|}
\hline Stimulus & N5 & N & F & R & S & PA \\
\hline MC & - & $\mathbf{. 6 7 6}$ & $\mathbf{. 7 8 0}$ & $\mathbf{. 6 3 2}$ & - & $\mathbf{. 7 6 0}$ \\
\hline BN & - & - & $\mathbf{. 7 3 6}$ & $\mathbf{. 7 6 2}$ & - & - \\
\hline NN_500 & - & - & - & - & - & - \\
\hline NN_2000 & - & - & - & - & - & - \\
\hline NN_8000 & - & - & $\mathbf{. 7 8 4}$ & $\mathbf{. 9 0 0}$ & - & - \\
\hline
\end{tabular}

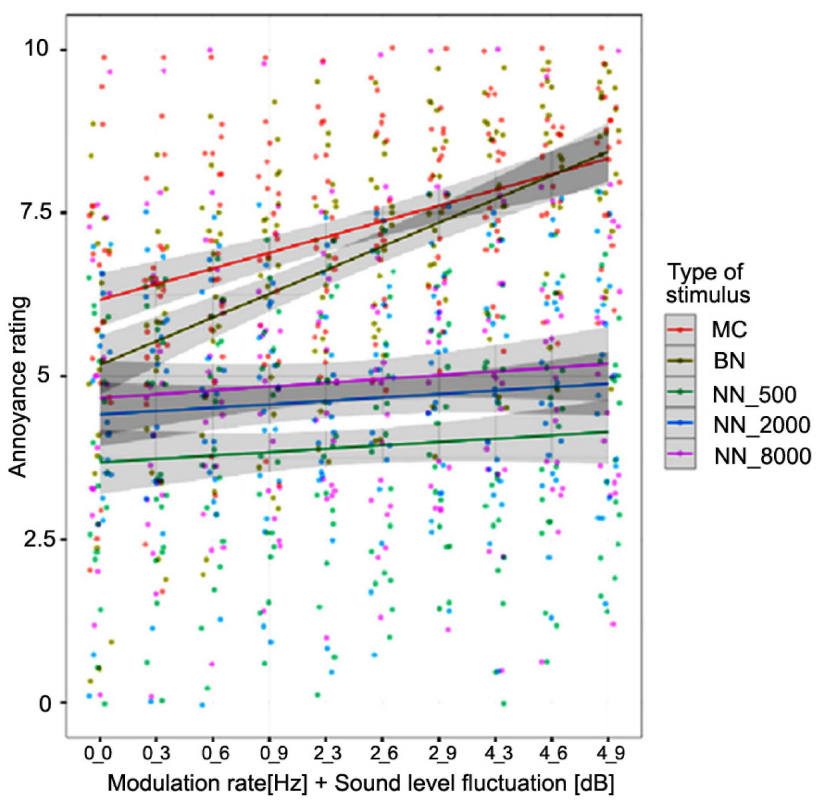

Fig. 6. Mean annoyance ratings with 95\%CI for five different type of investigated stimuli: MC, BN, NN_500, NN_2000, NN_8000 for all level of index of the disturbance. 
As expected, there is only a significant correlation between the time-dependent noise characteristics and the ICBEN annoyance ratings: for fluctuation strength $(\mathrm{F})$ and for roughness $(\mathrm{R})$. This occurs for broadband noise (BN), car noise (MC) and narrowband noise NN_8000 Hz. However, the changes of these time-dependent noise characteristics were not strong enough to influence the changes in psychoacoustic annoyance (PA), with the exception of MC stimuli.

\section{Discussion and conclusions}

There is a different relationship between noise annoyance ratings of amplitude modulated sounds for broadband noise and narrowband noise. For broadband noises (MC and BN stimuli) noise annoyance ratings increase with the modulation rate, while for narrowband noises (NN_500, NN_2000, NN_8000) noise annoyance ratings do not change significantly with the modulation rate.

There is a significant difference between unmodulated and modulated sounds for broadband stimuli (with four exceptions), while there are no significant differences for narrowband noises (with five exceptions).

Four exceptions of the broadband stimuli are as follows: for $\mathrm{MC}$ stimuli there is no difference between MC_0_0 and MC_1_3 $(p=0.086)$, and for BN stimuli there is no difference between BN_0_0 and the stimuli BN_1_3, BN_1_6 and BN_1_9 $(p>0.05)$.

For the narrowband stimuli, exceptions apply to significant differences between unmodulated and modulated stimuli and they occur for three cases of the NN_500 stimulus: NN_500_1_9 $(p=0.012)$, N_500_2_9 $(p=0.003)$ and NN_500_4_9 $(p<0.001)$ and for two cases of NN_2000 stimulus: NN_2000_2_9 $(p=0.006)$ and NN_2000_4_9 $(p=0.022)$.

For a given modulation rate the noise annoyance rating does not significantly increase with sound level fluctuations. This is true for all kinds of stimuli.

Although the real wind turbine noise recording was not assessed by the participants of the psychoacoustic experiment, its noise characteristics were compared with the investigated stimuli in this study. The most similar values of $\mathrm{F}, \mathrm{R}$ and $\mathrm{PA}$ are shown in red in Table 2. It is clear that both broadband noises, i.e. stimuli $\mathrm{MC}$ and $\mathrm{BN}$, have noise characteristics more similar to the characteristics of the real wind turbine noise recording than the narrowband stimuli.

Comparing the results of the noise annoyance ratings for broadband stimuli it is worth noting that for a modulation rate of to $1 \mathrm{~Hz}$ (typical for most wind turbine noise) the $\mathrm{MC}$ stimuli are perceived as more annoying than the BN stimuli. This result could support the conclusion that the low frequency components in wind turbine noise are not a real problem. As can be seen from the spectra of MC and BN stimuli (Figs. 3 and 4) there are more low frequency components in $\mathrm{BN}$ than in MC stimuli.

The following conclusions can be drawn from the results obtained in this study:

- The auditory system is most sensitive to amplitude modulation in the modulation-rate range between 2 and $5 \mathrm{~Hz}$, reaching a minimum near $4 \mathrm{~Hz}$. The results of this study show that the stimulus corresponding to this sensitivity minimum is the most annoying one. All broadband noise stimuli were judged more annoying when the modulation rate was $4 \mathrm{~Hz}$ than when it was $1 \mathrm{~Hz}$. From the practical point of view, noise generated by a wind turbine is perceived as less annoying when the frequency of amplitude modulation occurring in this noise is less than $4 \mathrm{~Hz}$.

- The JND for amplitude modulation depends on the bandwidth of the modulated stimulus and decreases when the bandwidth of the modulated stimulus is increased. This fact explains why narrowband stimuli were perceived as less annoying than broadband stimuli when the same time characteristics (modulation rate and sound level fluctuations) were applied to them.

- For the same time characteristics (modulation rate of $1 \mathrm{~Hz}$ and three values of level fluctuation $3,6,9 \mathrm{~dB}$ ) applied to two broadband stimuli, the less annoying stimulus is the one with a larger number of low frequency components, e.g. BN stimuli. This result supports the previous results (TACHIBANA, 2014; YOKOYAMA et al., 2013) which demonstrated that low frequency components are not the most significant problem when it comes to the annoyance perception of wind turbine noise.

- To be perceived as being as annoying as real wind turbine noise it is not enough for amplitude modulated noise to have the same time parameters (modulation rate and sound level fluctuations), but it also must have similar broadband spectral characteristics.

- A significant correlation between the annoyance ratings obtained from the participants of the experiment and calculated sound characteristics occurs for broadband noises (BN and MC stimuli) and NN_8000 stimulus for: fluctuation strength, roughness and psychoacoustic annoyance (only in case of MC stimuli).

\section{Acknowledgment}

This research was supported by a grant from the National Science Centre: Project Number UMO2011/03/B/HS6/03709. 


\section{References}

1. ANSI Specifications for Audiometers, American National Standards Institute, New York, ANSI S3, 1996; 6-1996.

2. Bakker R., Pedersen E., van den Berg G., StewART R., LOK W., Bouma J. (2012), Impact of wind turbine sound on annoyance, self-reported sleep disturbance and psychological distress, Sci. Total. Environ., 425, 42-51.

3. Berglund B., Berglund U., Lindvall T. (1976), Scaling loudness, noisiness, and annoyance of community noises, J. Acoust. Soc. Am., 60, 1119-1126.

4. Berglund B. (1991), Quality assurance in environmental psychophysics, [in:] Ratio scaling of psychological magnitudes - in honor of the memory of S.S. Stevens, Bolanowski S., Gescheider G. [Eds.], Hillsdale, New Jersey, L. Erlbaum Associates.

5. Bockstael A., Dekoninck L., Can A., Oldoni D., De Coensel B., Botteldooren D. (2012), Reduction of wind turbine noise annoyance: an operational approach, Acta Acust. Acust., 98, 392-401.

6. Bolin K., Bluhm G., Eriksson G., Nilsson M. (2011), Infrasound and low frequency noise from wind turbines: exposure and health effects, Environ. Res. Lett., 6, 035103.

7. Bolin K. (2009), Prediction method for wind-induced vegetation noise, Acta Acust. Acust., 95, 607-19.

8. Bolin K., Nilsson M., Shafiquzzaman K. (2010), The potential of natural sounds to mask wind turbine noise, Acta Acust. Acust., 96, 131-7.

9. Botteldooren D., Verkeyn A. (2002), Fuzzy models for accumulation of reported community noise annoyance from combined sources, J. Acoust. Soc. Am., 112, 1496-508.

10. Botteldooren D., Lavandier C., Preis A., Dubois D., Aspuru I., Guastavino C., Brown L., Nillson M., Andringa T.C. (2011), Understanding urban and natural soundscapes, Proceedings of Forum Acusticum 2011, Aalborg, Denmark.

11. Chang E., Merzenich M. (2003), Environmental noise retards auditory cortical development, Science, 300, 498-502.

12. De Coensel B., Botteldooren D., De Muer T., Berglund B., Nilsson M., Lercher P.A. (2009), Model for the perception of environmental sound based on notice-events, J. Acoust. Soc. Am., 126, 656-65.

13. Diaz C., Pedrero A. (2005), The reverberation time of furnished rooms in dwellings, Appl. Acoust., 66, 945-56.

14. Dittrich K., OBerfeld D. (2009), A comparison of the temporal weighting of annoyance and loudness, J. Acoust. Soc. Am., 126, 3168-3178.

15. Fastl H., Zwicker E. (2007), Psychoacoustics: Facts and Models, Berlin, Springer Verlag.
16. FÉGeAnt O. (1999), Wind-induced vegetation noise. Part 1: a prediction model, Acta Acust. Acust., 85, 228-40.

17. FÉGEANT O. (2002), Masking of wind turbine noise: Influence of wind turbulence on ambient noise fluctuations, Technical report 12, Sweden: Department of Civil and Architectural Engineering, Royal Institute of Technology.

18. Fields J.M., De Jong R.G., Flindell I.H., Job R.F.S., Kurra S., Lercher P., Vallet M., Yano T., Guski R., Felscher-Suhr U., SchuMER R. (2001), Standardized general-purpose noise reaction questions for community noise surveys: Research and a recommendation, Journal of Sound and Vibration, 242, 4, 641-679.

19. Fritz J., Elhilali M., David S., Shamma S. (2007), Auditory attention - focusing the searchlight on sound, Curr. Opin. Neurobiol., 17, 437-55.

20. Hellman R.P. (1982), Loudness, annoyance, and noisiness produced by single-tone-noise complexes, J. Acoust. Soc. Am., 72, 62-73.

21. Hubbard H., Shepherd K. (1991), Aeroacoustics of large wind turbines, J. Acoust. Soc. Am., 89, 2495-508.

22. ISO 8253-1:1989. Acoustics - audiometric test methods - part 1: basic pure tone air and bone conduction threshold audiometry. Geneva, Switzerland: International Organisation for Standardisation, 1989.

23. ISO 9613-1:1996. Acoustics - attenuation of sound during propagation outdoors - part 1. Geneva, Switzerland: International Organisation for Standardisation, 1996.

24. ISO 9613-2:1996. Acoustics - attenuation of sound during propagation outdoors - part 2. Geneva, Switzerland: International Organisation for Standardisation, 1996.

25. ISO 15666:2003(E). Acoustics - assessment of noise annoyance by means of social and socio-acoustical surveys, Geneva, Switzerland, ISO/TS, 2003.

26. ISO 18233:2006. Acoustics - application of new measurement methods in building and room acoustics. Geneva, Switzerland: International Organisation for Standardisation, 2006.

27. ISO 3382-1:2009. Acoustics - measurement of room acoustic parameters - part 1: performance spaces. Geneva, Switzerland: International Organisation for Standardisation, 2009.

28. Jacobsen J. (2005), Infrasound emission from Wind Turbines, Journal of Low Frequency Noise, Vibration and Active Control, 24, 3, 145-155.

29. Janssen S., Vos H., Eisses A., Pedersen E.A. (2011), Comparison between exposure-response relationships for wind turbine annoyance and annoyance due to other noise sources, J. Acoust. Soc. Am., 130, 3746-53. 
30. Jonasson H. (2007), Acoustical source modeling of road vehicles, Acta Acust. Acust., 93, 173-84.

31. KrippendorfF K. (1980), Content Analysis, an Introduction to Its Methodology, Thousand Oaks, Sage Publications.

32. Lee S., Kim K., Choi W., Lee S. (2011), Annoyance caused by amplitude modulation of wind turbine noise, Noise Control Eng., 59, 38-46.

33. Legarth S.V. (2007), Auralization and assessment of annoyance from wind turbines, Proc. 2nd Int. Meeeting on Wind Turbine Noise, Lyon.

34. LerCher P. (1995), Distinguishing effects modifiers of psychological morbidity associated with traffic noise exposure, Epidemiology, S28, P085.

35. Li H., Chau C., TANG S. (2010), Can surrounding greenery reduce noise annoyance at home?, Sci. Total Environ., 408, 4376-84.

36. Miedema H.M.E., Oudshoorn C.G.M. (2001), Annoyance from Transportation Noise: Relationships with Exposure Metrics DNL and DENL and Their Confidence Intervals, Environmental Health Perspectives, 109, 4, 409-416.

37. Miedema H., Vos H. (2003), Noise sensitivity and reactions to noise and other environmental conditions, J. Acoust. Soc. Am., 113, 1492-504.

38. Miedema H.M.E., Vos H. (2004), Noise Annoyance from Stationary sources: relationships with Exposure Metric day-evening-night level (DENL) and Their Confidence Intervals, J. Acoust. Soc. Am., 116, 1, 334343.

39. Moler H., Pedersen C. (2011), Low-frequency noise from large wind turbines, J. Acoust. Soc. Am., 129, $3727-44$.

40. Moorhouse A., Hayes M., von Hünerbein S., Piper B., AdAms M. (2007), Research into aerodynamic modulation of wind turbine noise: final report, Technical Report. UK, Department for Business, Enterprise and Regulatory Reform.

41. Ohrström E., Barregånd L., Andersson E., Skånberg A., Svensson H., Angerheim P. (2007), Annoyance due to single and combined sound exposure from railway and road traffic, J. Acoust. Soc. Am., 122, 2642-52.

42. Palmer W.A. (2009), New explanation for wind turbine whoosh - wind shear, Proceedings of Third International Meeting on Wind Turbine Noise, Aalborg, Denmark; 2009.

43. Pedersen E., Larsman P. (2008) The impact of visual factors on noise annoyance among people living in the vicinity of wind turbines, J. Environ. Psychol., 28, 379-89.

44. Pedersen E., Persson-Waye K. (2004), Perception and annoyance due to wind turbine noise - a doseresponse relationship, J. Acoust. Soc. Am., 116, 346070.
45. Pedersen E., Persson-Waye K. (2007), Wind turbine noise, annoyance and self-reported health and well-being in different living environments, Occup. Environ. Med., 64, 480-6.

46. Pedersen E., van den Berg F., Bakker R., Bouma J. (2009), Response to noise from modern wind farms in The Netherlands, J. Acoust. Soc. Am., 126, $634-43$.

47. Pedersen E., van den Berg F., Bakker R., Bouma J. (2010), Can road traffic mask sound from wind turbines? Response to wind turbine sound at different levels of road traffic sound, Energy Policy 38, 2520-7.

48. PersonWaye K., Öhström E. (2002), Psychoacoustic characters of relevance for annoyance of wind turbine noise, J. Sound. Vib., 250, 1, 65-73.

49. Preis A., Kaczmarek T., Wojciechowska H., Zera J., Fields J.M. (2003), Polish version of the standardized noise reaction questions for the community noise surveys, Int. J. Occup. Med. Environ. Health., 16, 2, 155-159.

50. QuirT J. (1983), Sound transmission through windows II. Double and triple glazing, J. Acoust. Soc. Am., 74, $534-42$

51. R Core Team (2015), R: A language and environment for statistical computing. $R$ Foundation for Statistical Computing, Vienna, Austria. URL http://www.Rproject.org/.

52. Salt A., Hullar T. (2010), Responses of the ear to low frequency sounds, infrasound and wind turbines, Hear. Res., 268, 12-21.

53. Schutte M., Marks A., Wenning E., Griefahn B. (2007), The development of the noise sensitivity questionnaire, Noise Health, 9, 15-24.

54. TAChiBana H. (2014), Synthetic research of wind turbine noise in Japan, Forum Acusticum, 7-12 September 2014 Kraków, Poland.

55. VAN DEN BERG G. (2004), Effects of the wind profile at night on wind turbine sound, J. Sound Vib., 277, 955-70.

56. VAN DEN BERG G.P. (2005), The beat is getting stronger:the effect of atmospheric stability on low frequency modulated sound of wind turbines, Journal of Low Frequency Noise, Vibration and Active Noise Control, 24, 1.

57. VAN DEN BERG F. (2009), Why is turbine noise noiser than other noise?, Proc. Euronoise, Edinburgh.

58. Van Gerven P., Vos H., Boxtel M., Janssen S., Miedema H. (2009), Annoyance from environmental noise across the lifespan, J. Acoust. Soc. Am., 126, 187-94.

59. Van Renterghem T., Bockstael A., De Weirt V., BotTeldooren D. (2013), Annoyance, detection and recognition of wind turbine noise, Science of the Total Environment, 456-457, 333-345. 
60. Van Renterghem T., Botteldooren D. (2012), Focused study on the quiet side effect at dwellings highly exposed by road traffic noise, Int. J. Environ. Res. PublicHealth, 9, 4292-310.

61. Viollon S., Lavandier C., Drake C. (2002), Influence of visual setting on sound ratings in an urban environment, Appl. Acoust., 63, 493-511.

62. Warren C., Lumsden C., O’Dowd S., Birnie R. (2010), Green on green: public perceptions of wind power in Scotland and Ireland, J. Environ. Plann Manag., 48, 853-75.

63. Weinstein N. (1978), Individual differences in reactions to noise: a longitudinal study in a college dormitory, J. Appl. Psychol., 63, 458-66.

64. Yokoyama S., Sakamoto S., Tachibana H. (2013), Study on the amplitude modulation of wind turbine noise: part 2 - Auditory experiments, Internoise 2013, Innsbruck. 